\title{
Challenges in Managing Pericardial Disease Related to Post Viral Syndrome After COVID-19 Infection
}

\author{
Zachary W. Sollie ${ }^{1}$, Shirisha R. Vallepu ${ }^{2}$, Cindrel Tharumia Jagadeesan ${ }^{3}$, Lori C. White ${ }^{2}$, Vishnu \\ Nagalapuram ${ }^{2}$ \\ 1. Internal Medicine, University of Alabama at Birmingham School of Medicine, Birmingham, USA 2. Internal Medicine, \\ University of Alabama at Birmingham, Montgomery Internal Medicine, Montgomery, USA 3. Internal Medicine, St. \\ Joseph's Hospital and Medical Center / Creighton University, Phoenix, USA
}

Corresponding author: Zachary W. Sollie, zsollie@uab.edu

\begin{abstract}
Although primarily a respiratory illness, coronavirus disease 2019 (COVID-19) has been associated with cardiac involvement with reported cases of myocardial ischemia, arrhythmia, myocarditis, pericarditis, and pericardial effusion leading to cardiac tamponade. Most cases of pericardial disease in this setting have been during the acute infection. Here, we present a patient who developed pericarditis leading to cardiac tamponade after the resolution of the acute COVID-19 infection. Her course of illness was further complicated by poor response to initial medical therapy with non-steroidal anti-inflammatory drugs (NSAIDs) and colchicine which could possibly be related to early exposure to steroids. It is often difficult to establish an underlying etiology for acute pericarditis. Similarly, in our case, although there is no definitive test to prove the causal relationship, this effusion is highly suspicious of being secondary to post viral sequelae after COVID-19 infection when considering the clinical course. It is important to consider pericardial disease as a late complication of COVID-19 even after apparent resolution of the acute infection and be mindful of the therapeutic challenges that we might face while managing such patients.
\end{abstract}

Review began 02/05/2021 Review ended 02/14/2021 Published 02/20/2021

\section{๑) Copyright 2021}

Sollie et al. This is an open access article distributed under the terms of the Creative Commons Attribution License CC-BY 4.0., which permits unrestricted use, distribution, and reproduction in any medium, provided the original author and source are credited.

Categories: Cardiology, Internal Medicine

Keywords: post viral syndrome, viral pericarditis, pericardial disease, covid-19, cardiac tamponade

\section{Introduction}

Coronavirus disease 2019 (COVID-19), a novel virus within the coronavirus family, was first described in December of 2019 [1]. While the primary concern of this virus is its potentially devastating pulmonary disease, it was quickly determined that there were numerous extra-pulmonary manifestations of this virus, including renal, gastrointestinal, liver, cardiac, mediastinal, neurologic, hematologic, vascular, cutaneous, reproductive, and ocular complications [2]. A wide variety of pathologies related to cardiac involvement in COVID-19 have been reported $[3,4]$. In particular, the pericardial disease has been increasingly recognized to complicate the course of illness, given very little direction on management strategies. Acute pericarditis, myopericarditis, pericardial effusion, and cardiac tamponade have been reported so far but mostly in the setting of an acute infection with COVID-19 in conjunction with respiratory symptoms of the disease [5-8]. Only a few cases have been reported with cardiac manifestations as the sole presentation or as a late complication $[9,10]$. Here, we present a patient who presented with pericardial effusion leading to tamponade as post-viral sequelae of COVID-19, which was further complicated by a protracted disease course.

\section{Case Presentation}

A 29-year-old previously healthy African American lady was diagnosed with COVID-19 in the middle of June 2020 when she had myalgia, fatigue, and headache following close contact with a friend who had a COVID19 infection. She was given a course of steroid taper at an urgent care center. Given the mild nature of the disease, she required only supportive therapy at home along with self-isolation. After three weeks, she tested negative and was cleared from home quarantine. Three days after testing negative, she presented to the hospital with chest pain and shortness of breath. At that time, an electrocardiogram (EKG) showed sinus tachycardia, and an echocardiogram showed mild pericardial effusion of less than $1 \mathrm{~cm}$. Significant labs upon presentation included negative troponins, erythrocyte sedimentation rate (ESR) of $74 \mathrm{~mm}$ per hour, Creactive protein (CRP) of $3.39 \mathrm{mg} / \mathrm{dL}$, COVID-19 immunoglobulin G of $68.9 \mathrm{AU} / \mathrm{mL}$, anti-nuclear antibodies negative, and negative human immunodeficiency virus (Table 1). She was diagnosed with acute pericarditis and was discharged with a combination of colchicine and ibuprofen. 


\section{Cureus}

\begin{tabular}{|c|c|c|c|}
\hline & Acute pericarditis presentation & Cardiac tamponade presentation & Lab reference values \\
\hline ESR & $74 \mathrm{~m} / \mathrm{hr}$ & 62 mm/hr & $0-20 \mathrm{~mm} / \mathrm{hr}$ \\
\hline CRP & $3.39 \mathrm{mg} / \mathrm{dL}$ & $6.6 \mathrm{mg} / \mathrm{dL}$ & $<0.8 \mathrm{mg} / \mathrm{dL}$ \\
\hline Troponin & $<2.5 \mathrm{ng} / \mathrm{L}$ & $<2.5 n g / \mathrm{dL}$ & $2.5-34.11 \mathrm{ng} / \mathrm{L}$ \\
\hline ANA screen & Negative & & \\
\hline COVID-19 lgG & $68.9 \mathrm{AU} / \mathrm{mL}$ & & $<1.4 \mathrm{AU} / \mathrm{mL}$ \\
\hline HIV screen & Negative & & \\
\hline \multicolumn{4}{|l|}{ Pericardial fluid } \\
\hline Appearance & & Opaque & \\
\hline Color & & Bloody & \\
\hline WBC & & $5,681 / \mathrm{mm}^{3}$ & \\
\hline $\mathrm{RBC}$ & & $163,000 / \mathrm{mm}^{3}$ & \\
\hline Manual monocytes & & $42 \%$ & \\
\hline Manual PMN & & $56 \%$ & \\
\hline Eosinophils & & $2 \%$ & \\
\hline Protein & & $5.2 \mathrm{gm} / \mathrm{dL}$ & \\
\hline LDH & & $511 \mathrm{mU} / \mathrm{mL}$ & \\
\hline Albumin & & $3.3 \mathrm{gm} / \mathrm{dL}$ & \\
\hline Bacterial culture & & Negative & \\
\hline AFB & & Negative & \\
\hline
\end{tabular}

\section{TABLE 1: Laboratory investigation}

ESR - erythrocyte sedimentation rate; CRP - C-reactive protein; ANA - anti-nuclear antibodies; WBC - white blood cells; RBC - red blood cells; PMN - polymorphonuclear leukocyte; LDH - lactate dehydrogenase; AFB - acid-fast bacilli; IgG - immunoglobulin G; COVID-19 - coronavirus disease 2019; HIV - human immunodeficiency virus

Five days following her initial discharge, she returned to the emergency department due to progressively worsening chest pain and exertional dyspnea. On presentation, her vital signs revealed a heart rate of 118 beats per minute and blood pressure of $111 / 85 \mathrm{~mm}$ Hg. Physical exam revealed a young woman in apparent distress, jugular venous pulse elevated to the mandible, and distant heart sounds with no rubs or murmurs. Pulsus paradoxus was noted upon further examination. Her EKG showed electrical alternans (Figure 1), and a computed tomography (CT) angiogram of the chest done to evaluate for pulmonary embolism revealed a large circumferential pericardial effusion (Figures 2-3). An echocardiogram revealed an increased effusion from her study seven days prior at greater than $3.5 \mathrm{~cm}$ and evidence of the diastolic collapse of the right ventricle (Figure 4). Upon recognizing the diagnosis, she underwent emergent pericardiocentesis, where 900 $\mathrm{mL}$ of serosanguinous fluid was drained. The pericardial fluid analysis revealed white blood cell count of $5,681 / \mathrm{mm}^{3}$, red blood cell count of $163,000 / \mathrm{mm}^{3}$, protein of $5.2 \mathrm{gm} / \mathrm{dL}$, lactate dehydrogenase of 511 $\mathrm{mU} / \mathrm{mL}$, negative bacterial cultures, and negative acid-fast bacilli (Table 1). Testing for COVID- 19 in the pericardial fluid was not available at our center. A drain was left in place for approximately 24 hours to reassess accumulation. Following a 24-hour echocardiogram revealed minimal effusion, the drain was removed, and her symptoms improved. 


\section{Cureus}

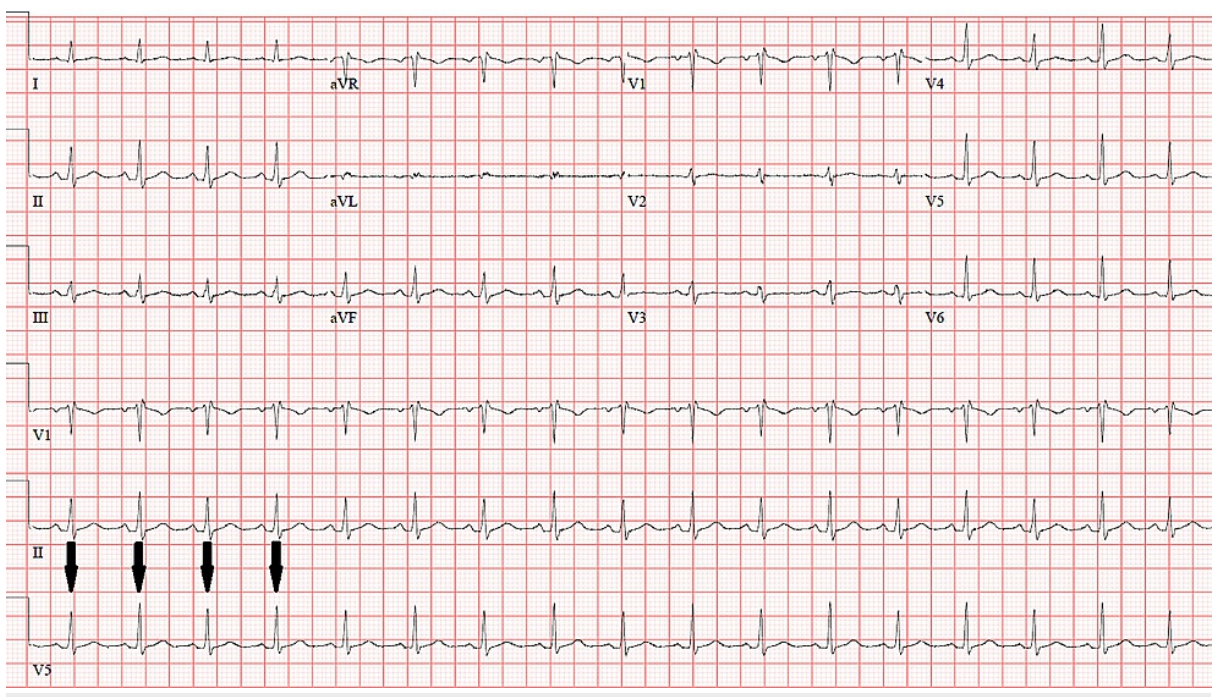

FIGURE 1: Electrocardiogram on return presentation demonstrating electric alternans

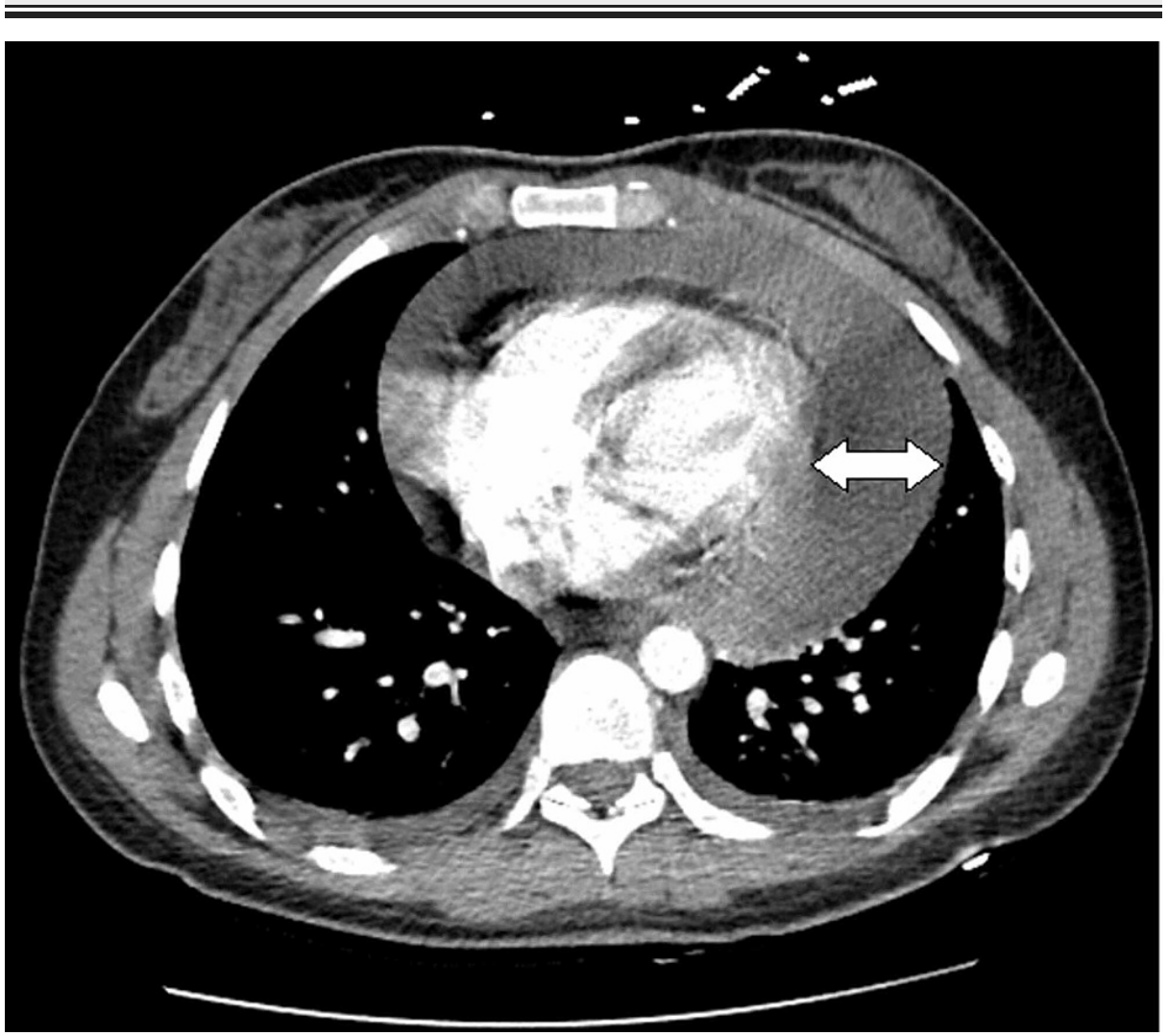

FIGURE 2: Axial view of the computed tomography angiogram of the chest revealing a large circumferential pericardial effusion 


\section{Cureus}

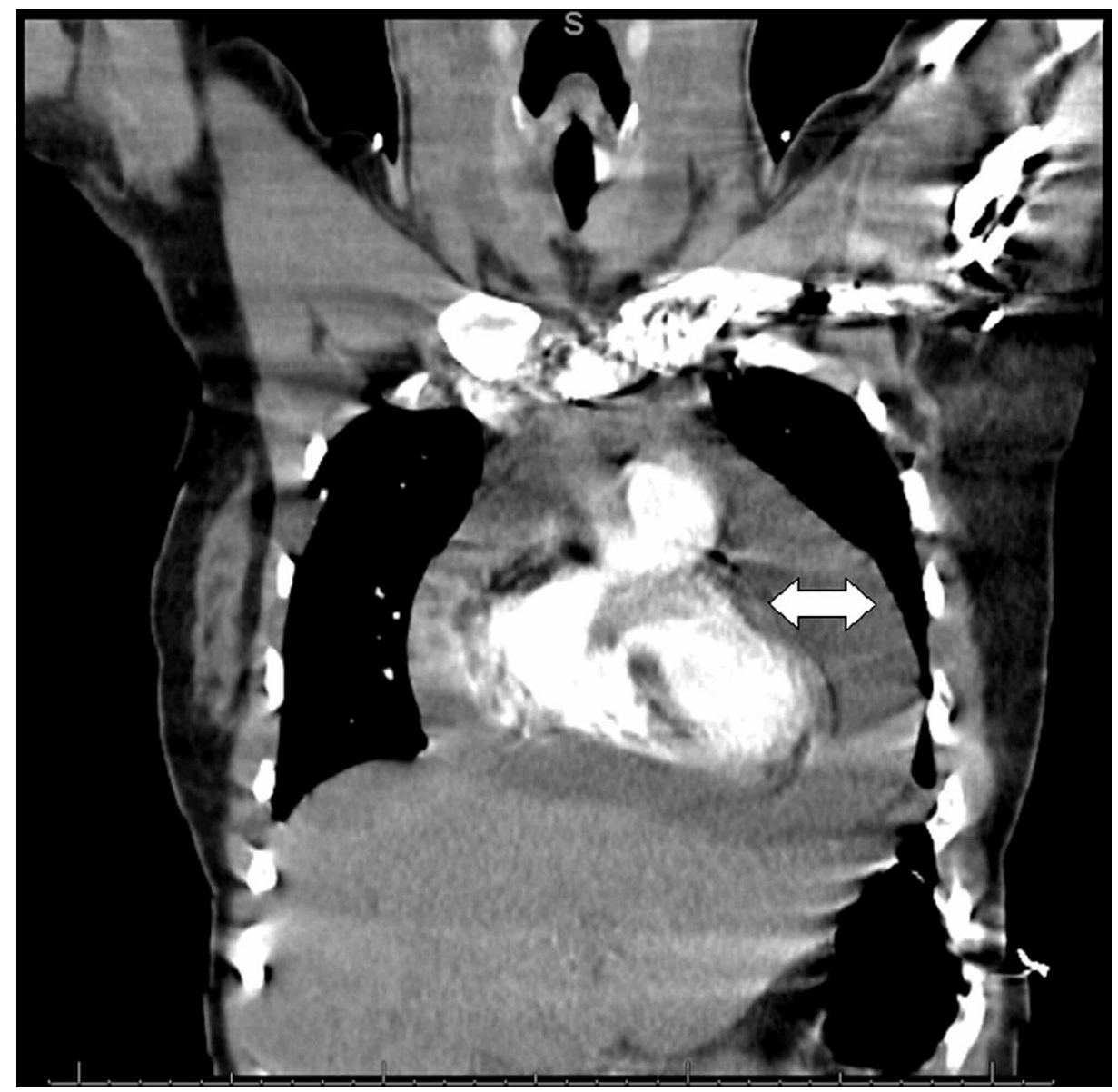

FIGURE 3: Coronal view of the computed tomography angiogram of the chest revealing a large circumferential pericardial effusion

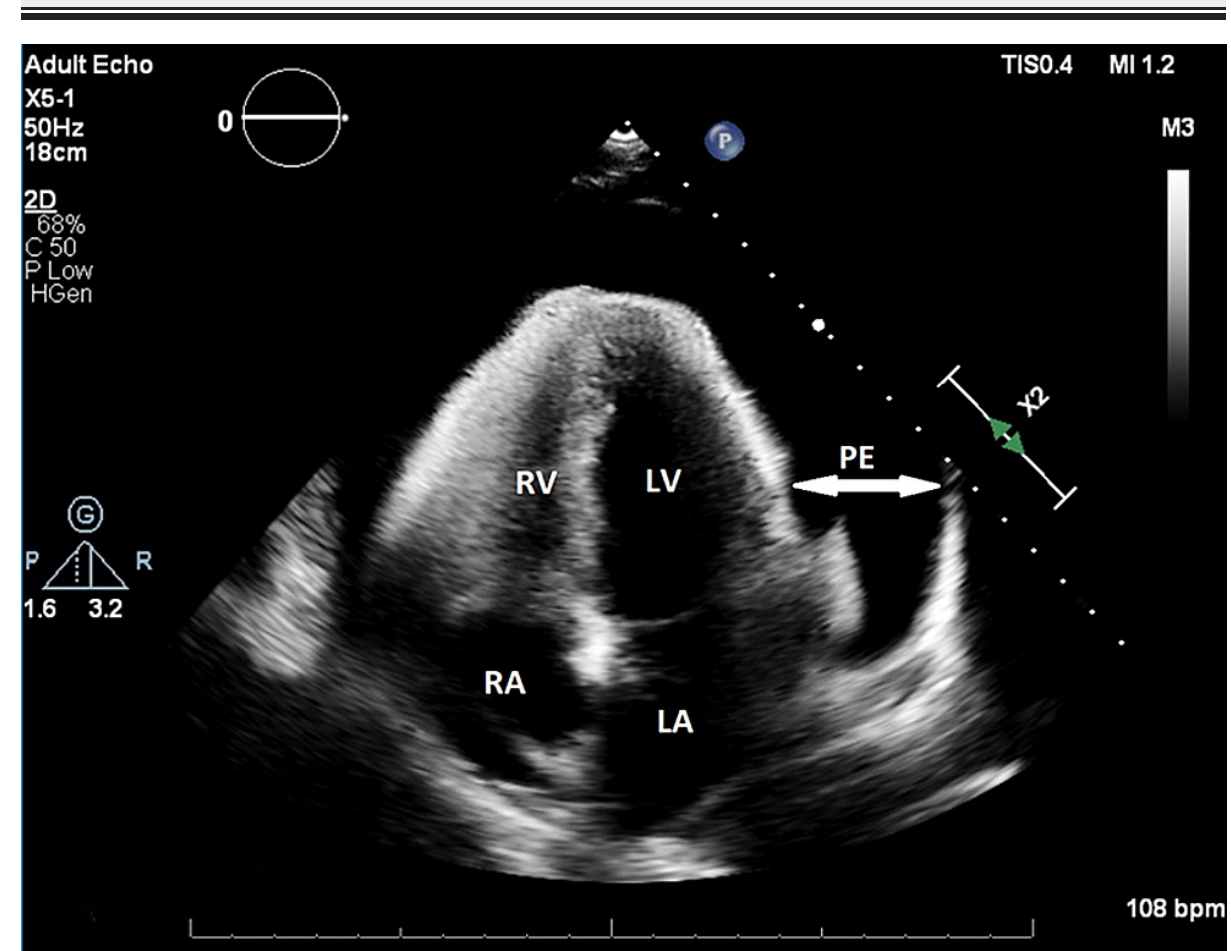

FIGURE 4: Apical four-chamber view of the 2D transthoracic echocardiogram revealing a large pericardial effusion 
Considering no response to ibuprofen, we managed her with a high dose of $325 \mathrm{mg}$ aspirin three times daily with a slow taper along with colchicine twice daily for three months. Adjunctive therapy consisted of pain management with opioids and incentive spirometry for atelectasis. Prior to discharge, she received a followup echocardiogram, which showed a stable effusion with a measurement of less than $1 \mathrm{~cm}$. During the hospital stay, surgical consultation for consideration of the pericardial window was obtained. Through shared decision-making, it was determined to reserve this procedure for recurrence or chronic course. Her symptoms persisted at her one-week follow-up, for which she was switched from taking aspirin to prednisone along with colchicine. Symptoms resolved with this regimen adjustment, and it was continued for three weeks followed by a three-month taper, at which point she didn't have any pericardial effusion on echocardiogram.

\section{Discussion}

Since the beginning of the COVID-19 pandemic, pericardial disease related to COVID- 19 has been reported increasingly. The range of presentations with this pathology varies, including pericarditis as the sole primary presentation of COVID-19 infection, pericarditis in conjunction with respiratory symptoms, pericardial effusion with or without cardiac tamponade, pericarditis with features of myocarditis, and pericarditis in a pediatric patient [5-11]. At least two out of the following four are needed for the diagnosis of acute pericarditis: 1) chest pain; 2) pericardial rub; 3) EKG changes, and 4) new or worsening pericardial effusion [12]. This should hold true even in the context of COVID-19, whether acute or as a post-viral syndrome. No specific biomarker is available to diagnose pericarditis. However, inflammatory markers like ESR, CRP, leukocyte count, and imaging modalities, including chest roentgenogram, CT scan, and echocardiogram, are often utilized to diagnose and monitor response to treatment. Cardiac specific biomarker - troponin - can be used to assess myocardial involvement. Advanced imaging like cardiac magnetic resonance should be reserved for ambiguous cases [13]. COVID-19 testing on the pericardial fluid is neither available widely nor validated. However, COVID-19 has been demonstrated in the pericardial fluid using reverse transcriptasepolymerase chain reaction and electron microscopy [14, 15]. Since management would not change depending on this, it is reasonable to avoid these investigations, which are often laborious and expensive. The yield of pericardial fluid analysis is often poor in establishing a viral etiology and can often be irrelevant clinically since most cases can be treated empirically without identifying a specific viral etiology [16]. A limitation to our case was the lack of further investigation for common viral etiologies that can lead to pericardial disease. While many other common viruses are known to have pericardial sequelae, the clinical picture of known recent COVID-19 infection was enough to raise suspicion. Furthermore, management of viral-related pericarditis likely would not have otherwise changed.

Medications that have been employed so far in pericardial disease related to COVID-19 include colchicine, NSAIDs including aspirin, steroids, and intravenous immunoglobulins (IVIG) [6, 7, 17]. Colchicine has been used alone or in combination with NSAIDs successfully [5, 7, 10]. Li et al. reported a case of a hemodynamically unstable patient with COVID-19 myopericarditis who responded well to IVIG and methylprednisolone [17]. At the beginning of the pandemic, there was some safety concern related to NSAIDs use in COVID-19 [18]. However, more recent data suggest no increased risk of severe adverse outcomes related to this [19]. Early use of steroids in non-COVID-19 related pericarditis has been linked to increased recurrence and poor long-term outcomes [20]. In our patient, we propose that her poor response to ibuprofen and aspirin, along with her protracted course, is likely related to early steroid exposure prescribed originally for her mild COVID-19 infection. This question should further be explored, but it is unlikely that we would have an answer soon, given how uncommon pericardial disease is in this setting. Hence, it is not unreasonable to continue to choose NSAIDs along with colchicine and avoid steroids for treating pericardial disease related to COVID-19 infection. Invasive interventions include pericardiocentesis more often than pericardiectomy [6-11].

Overall, acute pericarditis should be recognized in the setting of COVID-19, just like other viral infections. This can be related to the acute infection itself or as post-viral sequelae. Evaluation and diagnosis are largely the same. However, treatment modalities should be carefully selected. Diagnostic pericardiocentesis can be avoided if there are no high-risk features. A trial of colchicine can be considered in pericardial disease related to COVID-19. Anecdotally, a course of steroid taper is often prescribed by providers for mild COVID19 infection without a clear benefit. In order to provide the most benefit to the patient when steroids are needed, we feel it may be helpful to avoid steroids early in the course of the infection unless benefits related to hypoxia outweigh other risks. Other medications like NSAIDs, intravenous immunoglobulins, etc., should be individualized. Therapeutic pericardiocentesis is necessary for patients with cardiac tamponade. Pericardiectomy should be reserved for recurrent or chronic pericarditis as usual.

\section{Conclusions}

Pericardial disease as a cardiac manifestation of COVID-19, both in acute infection and as post-viral sequelae, should be promptly recognized. Steroids should be avoided in mild COVID-19 and in acute pericarditis since it could worsen the long-term outcomes of pericarditis itself. Colchicine can be considered 


\section{Additional Information \\ Disclosures}

Human subjects: Consent was obtained or waived by all participants in this study. Conflicts of interest: In compliance with the ICMJE uniform disclosure form, all authors declare the following: Payment/services info: All authors have declared that no financial support was received from any organization for the submitted work. Financial relationships: All authors have declared that they have no financial relationships at present or within the previous three years with any organizations that might have an interest in the submitted work. Other relationships: All authors have declared that there are no other relationships or activities that could appear to have influenced the submitted work.

\section{References}

1. Wang D, Hu B, Hu C, et al.: Clinical characteristics of 138 hospitalized patients with 2019 novel coronavirus-infected pneumonia in Wuhan, China. JAMA. 2020, 323:1061-1069. 10.1001/jama.2020.1585

2. Behzad S, Aghaghazvini L, Radmard, AR, Gholamrezanezhad A: Extrapulmonary manifestations of COVID19: radiologic and clinical overview. Clin Imaging. 2020, 66:35-41. 10.1016/j.clinimag.2020.05.013

3. Inciardi RM, Lupi L, Zaccone G, et al.: Cardiac involvement in a patient with coronavirus disease 2019 (COVID-19). JAMA Cardiol. 2020, 5:819-824. 10.1001/jamacardio.2020.1096

4. Gill GS, Vlacancich R, Mehta N, Chaturvedi M, Papolos A: Spectrum of cardiac involvement in COVID-19. Cureus. 2020, 12:e8638. 10.7759/cureus.8638

5. Ortiz-Martínez Y, Cabeza-Ruiz LD, Vásquez-Lozano SH, Villamil-Gómez WE, Rodriguez-Morales AJ: Pericarditis in a young internal medicine resident with COVID-19 in Colombia . Travel Med Infect Dis. 2020, 37:101863. 10.1016/j.tmaid.2020.101863

6. Naqvi SGZ, Naseeb U, Fatima K, Riffat S, Memon AG: Acute pericarditis and pericardial effusion in a hypertensive COVID-19 patient. Cureus. 2020, 12 :e10705. 10.7759/cureus.10705

7. Asif T, Kassab K, Iskander F, Alyousef T: Acute pericarditis and cardiac tamponade in a patient with COVID19: a therapeutic challenge. European J Case Rep Intern Med. 2020, 7: 10.12890/2020_001701

8. Hua A, O'Gallagher K, Sado D, Byrne J: Life-threatening cardiac tamponade complicating myo-pericarditis in COVID-19. Eur Heart J. 2020, 41:2130. 10.1093/eurheartj/ehaa253

9. Dalen H, Holte E, Guldal AU, et al.: Acute perimyocarditis with cardiac tamponade in COVID-19 infection without respiratory disease. BMJ Case Rep. 2020, 13:e236218. 10.1136/bcr-2020-236218

10. Fox K, Prokup JA, Butson K, Jordan K: Acute effusive pericarditis: a late complication of COVID-19. Cureus. 2020, 12:e9074. 10.7759/cureus.9074

11. Raymond TT, Das A, Manzuri S, Ehrett S, Guleserian K, Brenes J: Pediatric COVID-19 and pericarditis presenting with acute pericardial tamponade. World J Pediatr Congenit Heart Surg. 2020, 11:802-804. $10.1177 / 2150135120949455$

12. Lüscher TF (ed): European Heart Journal. 2015, 36:2873-2885. 10.1093/eurheartj/ehv479

13. Chiabrando JG, Bonaventura A, Vecchié A, et al.: Management of acute and recurrent pericarditis: JACC state-of-the-art review. J Am Coll Cardiol. 2020, 75:76-92. 10.1016/j.jacc.2019.11.021

14. Farina A, Uccello G, Spreafico M, Bassanelli G, Savonitto S: SARS-CoV-2 detection in the pericardial fluid of a patient with cardiac tamponade. Eur J Intern Med. 2020, 76:100-101. 10.1016/j.ejim.2020.04.045

15. García-Cruz E, Manzur-Sandoval D, Lazcano-Díaz EA, Soria-Castro E, Jiménez-Becerra S: Cardiac tamponade in a patient with myocardial infarction and COVID-19: electron microscopy. JACC Case Rep. 2020, 2:2021-2023. 10.1016/j.jaccas.2020.07.042

16. Permanyer-Miralda G, Sagristá-Sauleda J, Soler-Soler J: Primary acute pericardial disease: a prospective series of 231 consecutive patients. Am J Cardiol. 1985, 56:623-630. 10.1016/0002-9149(85)91023-9

17. Li A, Garcia-Bengochea Y, Stechel R, Azari BM: Management of COVID-19 myopericarditis with reversal of cardiac dysfunction after blunting of cytokine storm: a case report. Eur Heart J Case Rep. 2020, 4:1-6. 10.1093/ehjcr/ytaa224

18. Russell B, Moss C, Rigg A, van Hemelrijck M: COVID-19 and treatment with NSAIDs and corticosteroids: should we be limiting their use in the clinical setting?. Ecancer. 2020, 14:1023. 10.3332/ecancer.2020.1023

19. Wong AYS, MacKenna B, Morton C, et al.: OpenSAFELY: do adults prescribed Non-steroidal antiinflammatory drugs have an increased risk of death from COVID-19?. Ann Rheum Dis. 2020, 10.1101/2020.08.12.20171405

20. Farand P, Bonenfant F, Belley-Côté EP, Tzouannis N: Acute and recurring pericarditis: more colchicine, less corticosteroids. World J Cardiol. 2010, 2:403-407. 10.4330/wjc.v2.i12.403 